\title{
Should antioxidant vitamin supplementation be applied in patients with metabolic syndrome? A case-control study
}

\author{
Małgorzata Godala ${ }^{1}$, Izabela Materek-Kuśmierkiewicz ${ }^{2}$, Dariusz Moczulski², Franciszek Szatko ${ }^{3}$, \\ Ewelina Gaszyńska3 ${ }^{3}$ Sławomir Tokarski ${ }^{4}$, Jan Kowalski ${ }^{5}$ \\ ${ }^{1}$ Department of Nutrition and Epidemiology, Chair of Hygiene and Epidemiology, Medical University of Lodz, Lodz, Poland \\ ${ }^{2}$ Department of Internal Medicine and Nephrodiabetology, Chair of Internal Diseases and Cardiology, Medical University of Lodz, Lodz, \\ Poland \\ ${ }^{3}$ Department of Hygiene and Health Promotion, Chair of Hygiene and Epidemiology, Medical University of Lodz, Lodz, Poland \\ ${ }^{4}$ Faculty of Medicine, University of Rzeszow, Rzeszow, Poland \\ ${ }^{5}$ Department of Internal and Infectious Diseases, Medical University of Lodz, Lodz, Poland
}

\begin{abstract}
Introduction: All cells in the human body are exposed to reactive oxygen species (ROS), which disturb the metabolic reactions in the organism. The antioxidant system in the human body consists of enzymatic and nonenzymatic mechanisms, among which vitamins $A, C$, and $E$ play a major role.

The aim of the study was to evaluate the supply of vitamins A, C, and E from daily food rations (DFR) in postmenopausal women with metabolic syndrome (MS) in relation to current nutrition standards.

Material and methods: The study involved 184 women with MS, aged 45-68 years (mean $57.38 \pm 8.17$ years). The control group comprised 90 women, aged 41-65 years (mean $57.48 \pm 5.79$ years) without MS. The food intake was assessed using 24-hour dietary recalls.

Results: The evaluation of intake of vitamins measured with daily food rations (DFR) demonstrated that the optimal level of $90-110 \%$ according to standards was achieved only in $3.62 \%$ of women with metabolic syndrome for vitamin A, in $8.88 \%$ for vitamin C, and in $11.41 \%$ for vitamin $\mathrm{E}$, which was significantly less often found than in the control group $(p<0.001)$.

Conclusions: Women with MS are characterised by diversified intake of vitamins $A, C$ and $E$, and a subgroup of this patients present low level of antioxidant vitamins intake. Supplementation with antioxidant vitamins should be prescribed individually to postmenopausal women with MS.
\end{abstract}

Key words: metabolic syndrome, antioxidant vitamins supplementation, diet, menopause.

\section{Introduction}

All cells in the human body are exposed to reactive oxygen species (ROS), which disrupt the metabolic processes in the mitochondria and disturb metabolic reactions in the organism. To protect against negative ROS effects, the organism developed defence mechanisms in the form of an antioxidant barrier, the efficient functioning of which is particularly important in the case of patients with metabolic syndrome (MS) in the pathogenesis of which oxidative stress plays a significant role.

Disorders related to MS increase the risk for developing type 2 diabetes and cardiovascular diseases, which have been the leading cause of death in Poland for years. The incidence of MS, regardless of the accepted diagnostic criteria, is increasing not only in developed but also in developing countries where the progress of civilisation is associated with overconsumption and lower level of physical activity [1, 2]. According to research studies, overconsumption is often not accompanied by increased intake of essential nutrients, including antioxidant vitamins, but above all, it is associated with an excess of consumed energy, resulting in positive energy balance leading to weight gain and obesity.

The antioxidant system in the human body consists of the enzymatic and non-enzymatic mechanisms, among which vitamins $A, C$, and $E$ play a significant role. The level of antioxidant compounds in cells is supported by their appropriate intake in the diet or by de novo synthesis. There are results of large population studies indicating that subjects with MS are characterised by low consumption of vegetables, fruits, and products typical of the Mediterranean diet, rich in antioxidant ingredients, including vitamins A, C, and E [3]. On the other hand, as it has been shown in numerous studies that patients with MS are characterised by increased 
oxidative stress and weakened antioxidant barrier compared to those without MS [4]. Thus, a properly balanced diet determines not only the homeostasis of the internal environment of the body, but can also significantly contribute to strengthening the antioxidant barrier in patients with MS.

\section{Aim of the study}

The aim of the study was to evaluate the supply of vitamins $A, C$, and $E$ from daily food rations (DFR) in patients with $M S$ in relation to the estimated average requirement (EAR) for vitamins $A$ and $C$ and adequate intake (AI) of vitamin $\mathrm{E}$.

\section{Material and methods}

\section{Study population}

The study involved 184 patients, aged 30-65 years (mean $57.4 \pm 8.3$ years), including 84 women aged 30-65 years (mean $57.4 \pm 8.9$ years) and 100 men aged 41-65 years (mean $57.4 \pm 7.6$ years). All of them were nonsmokers and in the last year they did not take any dietary supplements. The control group comprised 90 subjects, 55 men and 35 women, aged 41-65 years (mean $57.65 \pm 5.78$ years), clinically healthy, without MS.

\section{Metabolic syndrome (definition)}

The diagnosis of MS was established on the basis of International Diabetes Federation (IDF) criteria, stating the occurrence of abdominal obesity (waist circumference in women $\geq 80 \mathrm{~cm}$, in men $\geq 94 \mathrm{~cm}$ ) and at least two from the following risk factors: triglycerides $\geq 1.7$ $\mathrm{mmol} / \mathrm{l}$ or the treatment of this disorder, low HDL cholesterol level (in women $<1.3 \mathrm{mmol} / \mathrm{l}$, in men $<1.0 \mathrm{mmol} / \mathrm{l}$ ) or the treatment of this disorder, fasting glucose $\geq 6.1$ $\mathrm{mmol} / \mathrm{l}$ or treated type 2 diabetes, arterial blood pressure $\geq 130 / 85 \mathrm{~mm} \mathrm{Hg}$, or the treatment of hypertension [5].

\section{Anthropometric analyses}

Height was measured using a fixed stadiometer, and weight was taken with individuals wearing light clothes and no shoes on a digital scale with a capacity of $200 \mathrm{~kg}$ and accurate to the nearest $100 \mathrm{~g}$. Body mass index (BMI) was calculated as weight (kilograms) divided by height in square metres. Waist circumference was measured at the midpoint between the bottom of the rib cage and above the top of the iliac crest during minimal respiration.

\section{Nutritional evaluation}

The food intake was assessed using 24-hour dietary recalls $(24 \mathrm{HR})$, in accordance with the guidelines of the
National Food and Nutrition Institute of Warsaw [6, 7]. A total of 552 24-hour dietary recalls (three 24HR for each individual) were obtained from subjects with MS and 270 24-hour dietary recalls from subjects without MS by the interviewer, and the means of consumption were calculated for each nutrient. The "album of photographs of food products and dishes" of the National Food and Nutrition Institute of Warsaw was used to determine the normal size of the consumed portions [7].

The vitamin content in the DFR and the achievement of the standards were determined with "charts of nutritive values of products and foods" and "standards of human nutrition" using Diet 5.0 software (license No: 52/PD/2013), according to the National Food and Nutrition Institute of Warsaw $[6,8]$. The program takes into account the loss of vitamins during technological and culinary food processing at the level of $25 \%$ for vitamin A, $55 \%$ for vitamin C, and $25 \%$ for vitamin E [6-8].

The evaluation of the intake of selected vitamins was made by calculating the degree of achieved standards at the level of: estimated average requirement (EAR) for vitamins $A$ and $C$, and adequate intake (AI) for vitamin $\mathrm{E}$. The desired level of standards was established at 90-110\% [6]. The following parameters were analyzsed: MUFA - monounsaturated fatty acids; PUFA - polyunsaturated fatty acids; SFA - saturated fatty acids; cholesterol; proteins - animal proteins and plant proteins; carbohydrates - absorbable carbohydrates, sucrose, and fibre.

\section{Statistical analyses}

Statistical analysis was performed using Statistica 7.1 PL and Office 2010 software. The normal distribution was determined using the Shapiro-Wilk test. The Student's $t$ test was used when variables were characterised by a normal distribution. The Mann-Whitney $U$ test was used when at least one variable did not fit a normal distribution. In the case of the characteristics of nominal scales, the structure ratio displayed by percentage was calculated, and in comparison analysis the $\chi^{2}$ test was used. Correlations were assessed by Spearman's coefficient (Rho). $p<0.05$ was considered to be significant.

The study was approved by the Bioethics Committee of the Medical University of Lodz (No: RNN/556/10/ $\mathrm{KB}$ ). Written consent was obtained from all research participants.

\section{Results}

Clinical characteristics of studied women is shown in Table I. As expected, BMI, waist circumference, systolic and diastolic blood pressure, glucose, TG, and LDL cholesterol level were higher in MS patients, whereas HDL cholesterol level was lower in subjects with MS. 
Tab. I. Clinical characteristics of studied women

\begin{tabular}{|c|c|c|c|}
\hline \multirow[t]{2}{*}{ Parameter } & MS $(n=184)$ & Without MS $(n=90)$ & \multirow[t]{2}{*}{$p$-value } \\
\hline & Mean \pm SD/\% (n) & Mean \pm SD/\% (n) & \\
\hline Age [years] & $57.38 \pm 8.17$ & $54.78 \pm 5.79$ & $N S^{a}$ \\
\hline Sex [\% women] & $59.78(110)$ & $55.56(50)$ & $\mathrm{NS}^{\mathrm{a}}$ \\
\hline Type 2 diabetes [\%] & $47.28(87)$ & $27.78(25)$ & $<0.001^{c}$ \\
\hline Hypertension [\%] & $80.43(148)$ & $55.56(50)$ & $0.0432^{c}$ \\
\hline Body mass index $\left[\mathrm{kg} / \mathrm{m}^{2}\right]$ & $34.35 \pm 5.31$ & $27.61 \pm 2.72$ & $<0.0001^{a}$ \\
\hline Waist $[\mathrm{cm}]$ & $114.21 \pm 12.16$ & $97.31 \pm 9.94$ & $<0.0001^{a}$ \\
\hline Systolic blood pressure [mmHg] & $144.17 \pm 15.22$ & $129.03 \pm 12.31$ & $<0.0001^{\mathrm{b}}$ \\
\hline Diastolic blood pressure [mmHg] & $87.47 \pm 10.81$ & $81.45 \pm 7.92$ & $<0.0001^{\mathrm{b}}$ \\
\hline \multicolumn{4}{|l|}{ Plasma concentration } \\
\hline Glucose $[\mathrm{mmol} / \mathrm{l}]$ & $8.13 \pm 3.05$ & $5.56 \pm 0.54$ & $<0.0001^{b}$ \\
\hline Triglycerides [mmol/l] & $1.91 \pm 0.92$ & $1.43 \pm 0.32$ & $<0.0001^{\mathrm{b}}$ \\
\hline Total cholesterol $[\mathrm{mmol} / \mathrm{l}]$ & $4.56 \pm 1.26$ & $4.56 \pm 0.91$ & $N^{a}$ \\
\hline High-density lipoprotein [mmol/l] & $1.09 \pm 0.24$ & $1.27 \pm 0.24$ & $<0.0001^{a}$ \\
\hline Low-density lipoprotein [mmol/l] & $2.97 \pm 0.97$ & $2.91 \pm 0.81$ & $<0.0001^{a}$ \\
\hline
\end{tabular}

aStudent's $t$ test; ' ${ }^{\text {Mann-Whitney } U} \mathrm{U}$ test; ${ }^{\mathrm{c}} \chi^{2}$ test

NS - not significant

There were no significant differences in total cholesterol level between the MS group and the controls. Diabetes and hypertension were more prevalent in patients with MS than in healthy subjects. Age was not different between groups.
The dietary characteristics of the studied women is shown in Table II. The consumption of energy, protein, fat, carbohydrates, fibre, PUFA, MUFA, SFA, as well as vitamin $A, C$, and $E$ did not differ significantly between patients with MS and controls, except

Tab. II. Dietary characteristics of studied women

\begin{tabular}{|c|c|c|c|c|}
\hline \multirow[t]{2}{*}{ Parameter } & \multirow[t]{2}{*}{ Recommendations } & MS $(n=184)$ & Without MS $(n=90)$ & \multirow[t]{2}{*}{$p$-value } \\
\hline & & Mean \pm SD & Mean \pm SD & \\
\hline Total energy $[\mathrm{kcal} / \mathrm{d}]$ & & $2159.96 \pm 91.77$ & $1995.47 \pm 99.24$ & $\mathrm{NS}^{\mathrm{a}}$ \\
\hline Proteins [g] & & $101.67 \pm 44.72$ & $90.52 \pm 29.13$ & $\mathrm{NS}^{\mathrm{a}}$ \\
\hline Animal proteins [g] & & $69.66 \pm 33.98$ & $31.16 \pm 11.7$ & $0.0023^{a}$ \\
\hline Plant proteins [g] & & $32.01 \pm 14.65$ & $59.36 \pm 21.8$ & $0.0051^{\mathrm{a}}$ \\
\hline Carbohydrates [g] & & $283.39 \pm 150.78$ & $296.06 \pm 49.72$ & $\mathrm{NS}^{\mathrm{a}}$ \\
\hline Absorbable carbohydrates [g] & & $259.43 \pm 145.19$ & $264.82 \pm 39.42$ & $\mathrm{NS}^{\mathrm{a}}$ \\
\hline Sucrose [g] & & $69.13 \pm 31.50$ & $22.73 \pm 10.17$ & $0.0027^{a}$ \\
\hline Fibre $[g]$ & $20-40$ & $23.97 \pm 10.89$ & $28.24 \pm 9.8$ & $\mathrm{NS}^{\mathrm{a}}$ \\
\hline Fats [g] & & $78.25 \pm 30.50$ & $71.94 \pm 9.27$ & $\mathrm{NS}^{\mathrm{a}}$ \\
\hline Saturated fatty acids [g] & & $34.96 \pm 25.39$ & $28.42 \pm 7.40$ & $N S^{a}$ \\
\hline Monounsaturated fatty acids [g] & & $33.06 \pm 26.46$ & $30.17 \pm 6.91$ & $N^{a}$ \\
\hline Polyunsaturated fatty acids [g] & & $10.14 \pm 7.69$ & $13.08 \pm 3.42$ & $N S^{a}$ \\
\hline$n-6[g]$ & & $10.13 \pm 6.59$ & $10.18 \pm 2.49$ & $\mathrm{NS}^{\mathrm{a}}$ \\
\hline$n-3[g]$ & & $1.01 \pm 0.99$ & $3.91 \pm 0.96$ & $0.0049^{a}$ \\
\hline Cholesterol [mg] & $<300$ & $380.12 \pm 234.53$ & $260.18 \pm 67.32$ & $0.0002^{a}$ \\
\hline Vitamin $\mathrm{A}$ [ $\mu \mathrm{g}$ of retinol equivalent] & $500(\mathrm{EAR})$ & $1300.14 \pm 1043.86$ & $1173.00 \pm 535.32$ & $\mathrm{NS}^{\mathrm{a}}$ \\
\hline Vitamin C [mg] & $60(E A R)$ & $103.99 \pm 139.14$ & $93.30 \pm 127.95$ & $N^{a}$ \\
\hline $\begin{array}{l}\text { Vitamin E } \\
\text { [mg of } \alpha \text {-tocopherol equivalent] }\end{array}$ & $8(\mathrm{Al})$ & $8.85 \pm 5.59$ & $9.33 \pm 5.09$ & $\mathrm{NS}^{\mathrm{a}}$ \\
\hline
\end{tabular}

aMann-Whitney U test

$\mathrm{F}$ - female, $\mathrm{M}$ - male; NS - not significant; EAR - estimated average requirement; $\mathrm{Al}$ - adequate intake 
for cholesterol and sucrose, a higher consumption of which was noted in MS patients. Furthermore, significant differences were demonstrated in the pattern of protein and PUFA intake; namely, MS patients were characterised by higher consumption of animal protein and lower consumption of $n-3$ fatty acids than subjects without MS.

Age did not differentiate between groups. No significant differences were found in the intake of the tested vitamins between the MS patients and the controls. The mean intake of vitamin A in the MS group was $1300.14 \pm 1043.86 \mu \mathrm{g}$, and it was $260.03 \%$ of EAR. The mean intake of vitamin C in the MS group was 103.99 $\pm 139.14 \mathrm{mg}$, and it was $173.32 \%$ of EAR. The mean intake of vitamin $E$ in the MS group was $8.85 \pm 5.59 \mathrm{mg}$, and it was $110.63 \%$ of Al.

Vitamin A intake positively correlated with the intake of SFA (Rho $=0.55, p<0.001)$, MUFA (Rho $=0.51$, $p<0.001$ ), PUFA (Rho $=0.32, p<0.001$ ), cholesterol (Rho $=0.58, p<0.001)$, and fibre (Rho $=0.45, p<0.001$ ). Correlations were also found between vitamin $E$ intake and the intake of SFA (Rho $=0.24, p<0.001)$, MUFA (Rho $=0.40, p<0.001)$, PUFA (Rho=0.84, $p<0.001)$, cholesterol (Rho $=0.40, p<0.001)$, and fibre (Rho $=0.56$, $p<0.001)$. Vitamin C intake correlated only with the intake of fibre (Rho $=0.42, p<0.001)$. Moreover, a correlation was demonstrated among the intakes of antioxidant vitamins. The intake of vitamin A correlated with the intake of vitamin $\mathrm{E}$ ( Rho $=0.33, p<0.001$ ) and vitamin $C$ (Rho $=0.26, p<0.001$ ), and the intake of vitamin $C$ correlated with the intake of vitamin $E$ (Rho $=0.38, p<0.001$ ).

The evaluation of intake of vitamins measured with daily food rations (DFR) demonstrated that the optimal level of $90-110 \%$ according to standards was achieved only in $3.62 \%$ of women with metabolic syndrome for vitamin A, in $8.88 \%$ for vitamin C, and in $11.41 \%$ for vitamin $E$, which was significantly less often found than in the control group $(p<0.001)$ (Figs. 1-3).

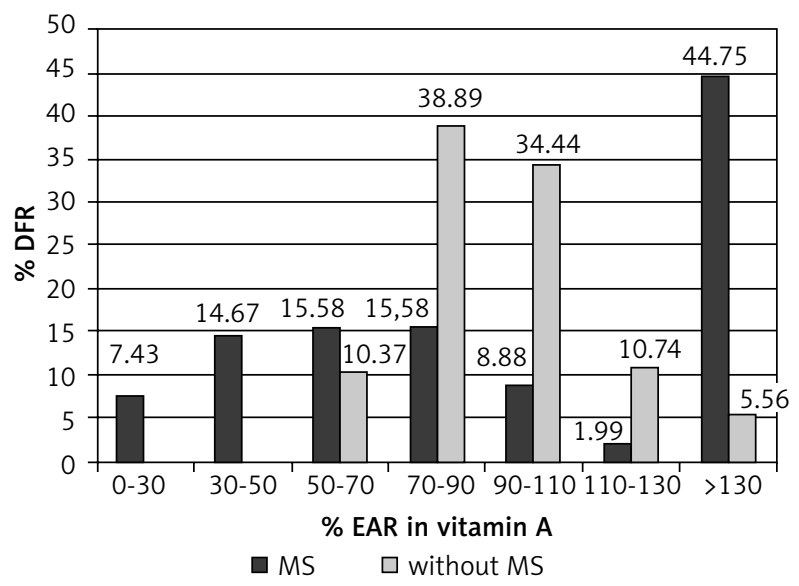

Fig. 2. The percentage of women who achieved ranges of DFR according to EAR in vitamin $C$
Insufficient intake of vitamin A measured with DFR was found in the case of $13.96 \%$ women with MS. The requirement determined by EAR exceeded $82.42 \%$ DFR. Insufficient intake of vitamin C measured with DFR was found in the case of $52.96 \%$ women with MS. The requirement determined by EAR exceeded $46.74 \%$ DFR. Insufficient intake of vitamin E measured with DFR was found in the case of $57.6 \%$ women with MS. The requirement determined by Al exceeded $30.98 \%$ DFR.

\section{Discussion}

Antioxidant vitamins play an important role in the prevention of metabolic and cardiovascular diseases. They are part of antioxidant barrier protecting the organism against ROS, therefore their supply in a diet should balance the demand determined by standards. Since the standards established by the National Food and Nutrition Institute concern the healthy population, it seems to be justified to advise patients with metabolic disorders, who are exposed to greater oxidative stress, to receive higher intake of vitamins $A, C$, and $E$ in their diet or in their supplementation [9-12].

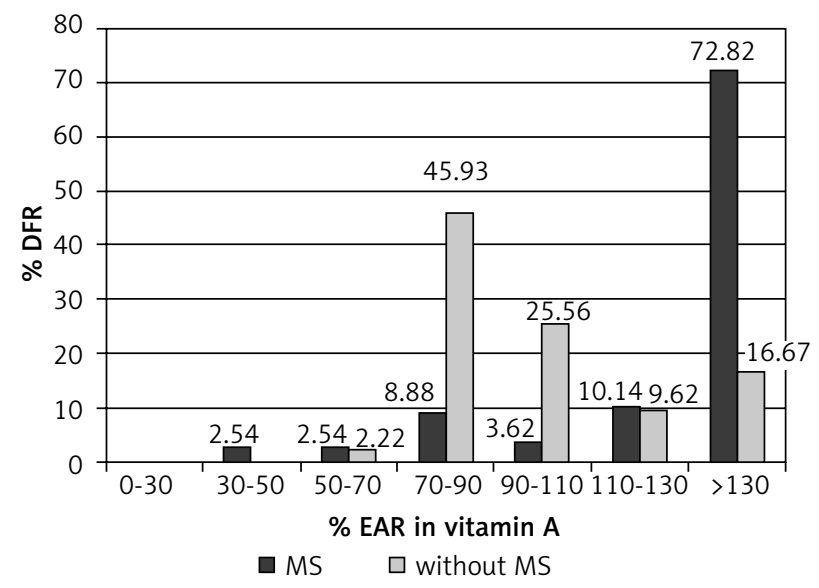

Fig. 1. The percentage of women who achieved ranges of DFR according to EAR in vitamin $A$

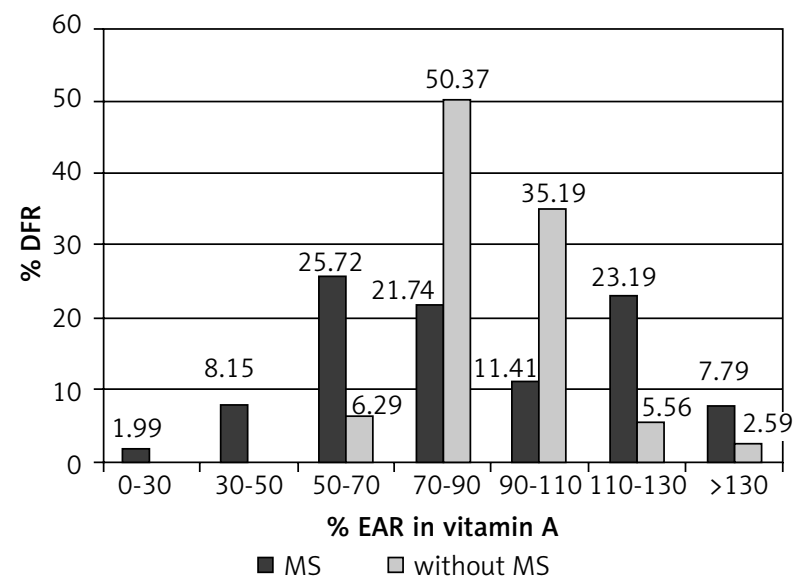

Fig. 3. The percentage of women who achieved ranges of DFR according to $\mathrm{Al}$ in vitamin $\mathrm{E}$ 
In our study, we found out that the average intake of vitamin A and C displayed by DFR in postmenopausal women with MS was high, exceeding the standard of EAR. In turn, the average intake of vitamin $E$ displayed by DFR did not differ from the standard of Al.

However, the analysis of the intake of these vitamins in patients with MS demonstrated that the desired level of $90-110 \%$ of the standard for vitamin A was achieved only in $3.62 \%$ of the patients, for vitamin C - in $8.88 \%$, whereas for vitamin E - in $11.41 \%$. On the other hand, in relation to vitamins $A$ and $C$, a large group of patients with MS exceeded the average requirement for these vitamins specified by the standard. In the case of vitamin $E$, over $57 \%$ did not have a sufficient intake of the vitamin.

Ostrowska et al. obtained similar results. They found a high intake of vitamins $A$ and $C$ among obese men and women [13]. Also Bronkowska et al. observed a high intake of antioxidant vitamins $A$ and $C$ among perimenopausal women [14]. Terlikowska et al., examining women aged 40-73 years, with hypertension, obesity, and metabolic syndrome, found the intake of vitamin $E$ at the level of $118 \%$ of EAR standard, whereas the intake of vitamins $C$ and $A$ did not deviate from the established standard [15]. Pachocka et al., examining patients with hypercholesterolaemia, found normal intake of antioxidant vitamins [16]. Stefańska et al., assessing the intake of vitamins in the diet by women with normal body weight, overweight, and obesity, observed higher intake of vitamins A, C, and E by obese women than by those with normal weight or overweight [17]. A high intake of antioxidant vitamins was also found in the diet of obese subjects with obstructive sleep apnoea [18].

In turn, the Multicentre Polish Population Health Status Study - WOBASZ - demonstrated normal content of vitamin C and E in the DFR [19]. Similar data were presented in the study evaluating the content of vitamins in the DFR of a selected Polish population [20]. However, Waszkiewicz-Robak et al. reported normal levels of intake of vitamins $A$ and $E$ in food rations of the Polish population and too low intake of vitamin C [21]. Troszczyńska et al., analysing the food rations of the Polish population, found that the content of fat-soluble vitamins was in accordance with the standard [22]. On the other hand, a study conducted by Nadolna et al. indicated too low intake of vitamins $A$ and $E$ by Polish adults [23].

The American NHANES study reported that the intake of vitamins A, C, and E was in accordance with the recommended standard, both in the group of healthy subjects and in those with MS [9]. A study performed among the inhabitants of Alaska gave similar results to those presented in the NHANES study [24]. In the study of Li et al. the intake of vitamin A and $E$ was consistent with the standard and did not differ signifi- cantly between patients with MS and healthy controls, whereas the intake of vitamin C in the group with MS was lower compared to healthy subjects [25]. In the study by Singh et al. the intake of vitamins $A, C$, and $E$ in patients with coronary heart disease did not differ from the standard and it was insignificantly lower compared to healthy subjects [26]. In a large French population study the intake of vitamins $C$ and $E$ was found to be in accordance with the standard [27]. Sohn et al., examining the Korean population, reported the intake of vitamin $A$ and $C$ to be in accordance with the standard [28]. However, Al-Daghri et al. reported in their study significantly lower intake of vitamins A, C, and $E$ in patients with MS compared to healthy subjects, and moreover, a significant percentage of the respondents did not receive the recommended nutrition standards (respectively, 37.5\%, 42.5\%, 98.7\%) [29].

The research carried out in Poland and other countries demonstrate that the intake of antioxidant vitamins is differentiated in subjects with intensified oxidative stress. Some researchers showed their normal intake, often even exceeding the requirements, while others demonstrated their too low supply in the diet. Thus, the issue of the introduction of antioxidant vitamins supplementation in patients with MS requires further research studies. The results of studies on the effect of the administered vitamin supplements on cardiovascular complications are controversial. Some authors demonstrated reduced oxidative stress, decreased risk for cardiovascular diseases, as well as reduced death rate after application of antioxidant vitamins supplementation [30-32]. Other authors did not demonstrate the efficacy of vitamin supplementation in the reduction of oxidative stress in these patients [31, 32]. There are also results of studies indicating the existence of factors disturbing and changing the effect of vitamin supplements that should be taken into account when planning the use of vitamin supplementation in patients with cardiovascular diseases. They include, among others, smoking and exposure to environmental chemical agents $[33,34]$.

To date, no optimal dose has been established of the supplements, as well as their composition, which, in the light of the available data, seems to be the key issue. In the case of individuals who consume insufficient amounts of antioxidant vitamins, changes in their eating habits and possible supplementation are justified. However, it should be determined whether the introduction of supplementation is justified in patients whose intake of antioxidant vitamins is in accordance with the instructions and even exceeds them several times, but which is not accompanied by their balanced serum levels. This was shown in our previous studies and confirmed by the results of other studies [33, 35, 36]. Excessive intake of antioxidant vitamins from the diet or vitamin preparations, especially in patients with 
a balanced deficiency, may increase oxidative stress and thus may lead to an increased risk of cardiovascular complications. In particular, this type of undesirable effect is attributed to vitamins C and E [30-32]. Moreover, in our study we have shown that patients with MS demonstrated a variety of nutritional standards related to the intake of vitamins $A, C$, and $E$, whereas in the group of healthy individuals the intake of the tested vitamins was fairly balanced and the percentage of those who were characterised by too high or too low intake was much lower than in the group of patients with MS. Perhaps the rationalisation of dietary intake of vitamins, not differing significantly from the recommendations, would normalise their plasma levels and would improve the antioxidant barrier in these patients without the need of vitamin supplementation.

However, in the case when the dietary supplementation of vitamins $A, C$, and $E$ is necessary, a very important issue seems to be the determination of the dose accompanied by an assessment of their dietary intake and plasma concentration individually for each patient.

\section{Conclusions}

Women with MS are characterised by diversified in take of vitamins $A, C$, and $E$, and a subgroup of this patients present low levels of antioxidant vitamins intake. Supplementation with antioxidant vitamins should be prescribed individually to postmenopausal women with MS.

\section{Disclosure}

\section{Authors report no conflict of interest.}

\section{References}

1. Lamb RE, Goldstein BJ. Modulating an oxidative-inflammatory cascade: potential new treatment strategy for improving glucose metabolism, insulin resistance, and vascular function. Int J Clin Pract 2008; 62: 10871095.

2. Ford ES. Prevalence of the metabolic syndrome defined by the International Diabetes Federation among adults in the USA. Diabetes Care 2005; 28: 2745-2749.

3. Fujita K, Nishizawa H, Funahashi T, et al. Systemic oxidative stress is associated with visceral fat accumulation and the metabolic syndrome. Circ J 2006; 70, 1437-1442.

4. Garcia-Bailo B, El-Sohemy A, Haddad PS, et al. Vitamins D, C, and E in the prevention of type 2 diabetes mellitus: modulation of inflammation and oxidative stress. Biologics 2011; 5: 7-19.

5. Alberti KG, Zimmet P, Shaw J, IDF Epidemiology Task Force Consensus Group. The metabolic syndrome - a new worldwide definition. Lancet 2005; 366: 1059-1062.

6. Jarosz M. Standards of Human Nutrition. National Food and Nutrition Institute, Warsaw 2012.

7. Szponar L, Wolnicka K, Rychlik E. Album of photographs of food products and dishes. National Food and Nutrition Institute, Warsaw 2000.

8. Kunachowicz H, Nadolna I, Przygoda B, Iwanow K. Charts of nutritive values of products and foods. Third edition expanded and updated. PZWL, Warsaw 2005.
9. Owczarczyk-Saczonek AB, Nowicki RJ. Prevalence of cardiovascular disease risk factors, and metabolic syndrome and its components in patients with psoriasis aged 30 to 49 years. Postep Derm Alergol 2015; 32: 290-295.

10. Stachowiak G, Pertyński T, Pertyńska-Marczewska M. Metabolic disorders in menopause. Prz Menopauzalny 2015; 14: 59-64.

11. Park K, Gross M, Lee $\mathrm{DH}$, et al. Oxidative stress and insulin resistance. Diabetes Care 2009; 58: 1812-1816.

12. Godala M, Materek-Kuśmierkiewicz I, Moczulski D, et al. Assessment of $25(\mathrm{OH})$ D vitamin concentration in plasma of residents of Lodz with metabolic syndrome in pre- and postmenopausal period. Prz Menopauzalny 2014; 13: 293-297.

13. Ostrowska I, Stefańska E, Czapska D, Karczewski J. Influence of nutrition in overweighted and obeese people on their lipids and carbohydrates. Bromat Chem Toksykol 2003; Suppl. 201-206.

14. Bronkowska M, Biernat J, Sadowska B. Assessment of vitamin intake with daily diets in perimenopausal women. Bromat Chem Toksykol 2009; 43: 18-23.

15. Terlikowska K, Dobrzycka B, Witkowska A, Zujko M. Assessment of selected vitamin and minerals in women aged 40-73 according to cardiovascular diseases risk factors. Bromat Chem Toksykol 2013; 46: 27-32.

16. Pachocka L, Bułhak-Jachymczyk B, Kłosiewicz-Latoszek L, et al. Antioxidant vitamins status in patients with combined hyperlipidemia. Ann Acad Med Stetin 2005; 51: 119-123.

17. Stefańska E, Ostrowska L, Czapska D, Karczewski J. Assessment of vitamin intake with daily diets by women with correct body mass, with overweight and obesity. Żywność Nauka Technologia Jakość 2009; 4: 286-294.

18. Bronkowska M, Gołecki M, Słomian J, et al. Evaluation of vitamin and mineral intake in the daily food rations of overweight and obese patients diagnosed with obstructive sleep apnea. Adv Clin Exp Med 2010; 19: 607-617.

19. Waśkiewicz A, Synowska E, Jasińska B, et al. Energy and nutrition value of polish diet. Results of WOBASZ program. Kard Pol 2005; 63: 663-669.

20. Szponar L, Ołtarzewski M, Rychlik E. Selected vitamins and minerals in daily diets among polish adults. Żyw Człow Metab 2002; 29: 114-118.

21. Waszkiewicz-Robak B, Dybkowska E, Świderski F. Vitamin antioxidants intake in Polish diet. Ann Univ Mariae Curie-Skłodowska (Med) 2005; 60 (supl. 16): 161-164.

22. Troszczyńska A: Healthy value of polish daily food rations - analytical research and theoretical assessment. Part VIII. Fat soluble vitamin intake. Żyw Człow Metab 2000; 27: 142-152.

23. Nadolna I, Kunachowicz H. Analitical research of daily food rations nutrition value. Part V. Retinol, $\beta$-carotene and vitamin E intake. Żyw Człow Metab 1994; 21: 243-252.

24. Fialkowski MK, McCrory MA, Roberts SM, et al. Estimated nutrient intakes from food generally do not meet dietary reference intakes among adult members of Pacific Northwest Tribal Nations. J Nutr 2010; 140: 992-998.

25. Li Y, Guo H, Wu M, Liu M: Serum and dietary antioxidant status is associated with lower prevalence of the metabolic syndrome in a study in Shanghai, China. Asia Pac J Clin Nutr 2013; 22: 60-68.

26. Singh RB, Ghosh S, Niaz MA, et al. Dietary intake, plasma levels of antioxidant vitamins, and oxidative stress in relation to coronary artery disease in elderly subjects. Am J Cardiol 1995; 76: 1233-1238.

27. Galan P, Viteri FE, Bertrais $S$, et al. Serum concentration of $\beta$-carotene, vitamins $C$ and $E$, zinc and selenium are influenced by sex, age, diet, smoking status, alcohol consumption and corpulence in a general French adult population. Eur J Clin Nutr 2005; 59: 1181-1190.

28. Sohn C, Kim J, Bae W. The framingham risk score, diet, and inflammatory markers in Korean men with metabolic syndrome. Nutr Res Pract 2012; 6: 246-253.

29. Al-Daghri NM, Khan N, Alkharfy KM, et al. Selected dietary nutrients and the prevalence of metabolic syndrome in adult males and females in Saudi Arabia: a pilot study. Nutrients 2013; 5: 4587-4604.

30. Li Y, Schellhorn HE. New developments and novel therapeutic perspectives for vitamin C. J Nutr 2007; 137: 2171-2184.

31. Pocobelli G, Ulrike P, Kristal AR, White E. Use of supplements of multivitamins, vitamin $C$, and vitamin $E$ in relation to mortality. Am J Epidemiol 2009; 170: 472-483. 
32. Soni MG, Thurmind S, Miller ER, et al. Safety of vitamins and minerals: controversies and perspective. Toxicol Science 2010; 118: 348-355.

33. Bergström T, Bergman J, Möller L. Vitamin A and C compounds permitted in supplements differ in their abilities to affect cell viability, DNA and the DNA nucleoside deoxyguanosine. Mutagenesis 2011; 26: 735744.

34. Mayne ST. Oxidative stress, dietary antioxidant supplements, and health: is the glass half full or half empty? Cancer Epidemiol Biomarkers Prev 2013; 22: 2145-2147.

35. Godala M, Materek-Kuśmierkiewicz I, Moczulski D, et al. Lower plasma levels of antioxidant vitamins in patients with metabolic syndrome: a case control study. Adv Clin Exp Med [in press].

36. Godala M, Materek-Kuśmierkiewicz I, Moczulski D, et al. Estimation of plasma vitamin A, C and E in patients with metabolic syndrome. Pol Mer Lek 2014; 36: 320-324 